\title{
The Foot Care Process of Diabetic Patients (With and Without Foot Ulcer) Attending A Tertiary Care Hospital in India
}

\author{
Ashok Kumar ${ }^{1}$, Adarsh Ranjan ${ }^{2}$, Gyan Chand ${ }^{3 *}$, Dinesh Kumar ${ }^{4}$, Sandeep Kumar Singh ${ }^{5}$ and Vijay Kumar \\ ${ }^{1}$ Department of Medical Genetics, Sanjay Gandhi Post Graduate Institute of Medical Sciences (SGPGIMS) Lucknow, India \\ ${ }^{2}$ Department of Nursing, Sanjay Gandhi Post Graduate Institute of Medical Sciences (SGPGIMS) Lucknow, India \\ ${ }^{3}$ Department of endocrinology, Sanjay Gandhi Post Graduate Institute of Medical Sciences (SGPGIMS) Lucknow, India \\ ${ }^{4}$ Department of Chemistry, Dr. Ram Manohar Lohia Avadh University Faizabad, India \\ ${ }^{5}$ Department of Neurology, Sanjay Gandhi Post Graduate Institute of Medical Sciences (SGPGIMS) Lucknow, India
}

\begin{abstract}
Diabetes Mellitus (DM) foot complications are a leading cause of morbidity in developing countries and prevalence of diabetes is expected to increase in the next decades in these countries. The aim of this study was to assess the knowledge about diabetic foot care among diabetic patients (with and without foot ulcer i.e. DFU+VE and DFU-VE) attending tertiary care hospitals (SGPGIMS, Lucknow) in India. This is a comparative study carried out from July 2013 to June 2014 based on questionnaires. The knowledge and practice scores, hypoglycaemia and diet score, and insulin administration and exercise score were classified as good if score $\geq 70 \%$, satisfactory if score was 50 $69 \%$ and poor if score was $<50 \%$. Among DFU+VE patients (200), $47.7 \%$ had good knowledge of foot care versus $52.3 \%$ had poor knowledge about foot care, $66.5 \%$ had good knowledge to treat hypoglycemia at home; $48.53 \%$ had good knowledge of insulin administration. In DFU-VE patients (200), $52 \%$ had good knowledge versus $48 \%$ had poor knowledge about foot care; $64.5 \%$ had good knowledge to treat hypoglycemia at home; $36.93 \%$ had good knowledge of insulin administration. Illiteracy and low socioeconomic status were significantly associated with poor knowledge and practice of foot care, hypoglycaemia and diet, and insulin administration and exercise in DFU+VE cases. This study has highlighted the deficiency of the knowledge of foot care among the DFU+VE and DFU-VE patients, underscores the need for an educational programme to reduce the diabetic foot complication.
\end{abstract}

Keywords: DFU+VE; DFU-VE; Foot ulcer; Foot care

\section{Introduction}

Diabetes mellitus (DM) is a metabolic disorder that is characterized by chronic hyperglycaemia; it is a common and potentially disabling chronic disease $[1,2]$. The condition is presently afflicting 194 million people worldwide and is estimated to rapidly increase to 333 million people in 2025 as a consequence of longer life expectancy, sedentary lifestyle and changing dietary patterns [2-4]. About $60 \%$ of the poorest countries in the world are in sub-Saharan Africa and this region will experience the greatest rise in the prevalence of diabetes in the next 20 year [3].

This rise in prevalence of DM is likely to bring a concomitant increase in its complications among diabetic patients. One important complication of DM are the foot problems; these complications constitute an increasing public health problem and are a leading cause of hospital admission, amputation of lower limb, pain and mortality in diabetic patients. In addition to causing pain and morbidity, foot lesions in diabetic patients also have substantial economic consequences, beside the direct costs of foot complications, there are also indirect costs relating to loss of productivity, individual patients' and family costs and loss of health related quality of life. The lifetime risk of a person with diabetes developing a foot ulcer could be as high as $25 \%$, and it is believed that every 30 seconds a lower limb is lost somewhere in the world as a consequence of diabetes [5]. The prevalence of diabetic foot ulcer (DFU) ranged between $1.0 \%$ and $4.1 \%$ in the United States (US), $4.6 \%$ in Kenya, and 20.4\% in Netherlands [6-8]. The International Diabetes Federation (IDF) estimates the total number of diabetic subjects to be around 40.9 million in India and this is further set to rise to 69.9 million by the year 2025 [9].

Some environmental factors like increasing urbanization, unhygienic conditions, poverty, frequent co-existing HIV infection, barefoot walking, low income, and cultural practices have also been said to compound the situation [10]. People with diabetes are prone to develop foot ulcer, amputation and other lower extremity clinical abnormalities if they do not have good knowledge of foot care practice. Therefore, the aim of the study was to educate the diabetic patients, at primary level, about foot care, hypoglycaemia, diabetic diet, insulin administration and exercise to reduce the foot complications produced by the diabetes knowledge about diabetes and care of foot can reduces the foot ulceration and amputation of foot of the patients and preventing the foot ulcer. The related objectives are:

(1) To assess the knowledge of diabetic patients about diabetes (symptoms, complication and foot complication)

(2) To assess the knowledge of diabetic patients about foot care

(3) To assess the knowledge of diabetic patients about hypoglycaemia.

(4) To assess the knowledge of diabetic patients about diabetic diet.

(5) To assess the knowledge of diabetic patients about insulin administration.

*Corresponding author: Dr. Gyan Chand, Additional Professor, Department of Endocrinology, Sanjay Gandhi Post Graduate Institute of Medical Sciences Lucknow-226014, India, Tel: +91-5222494359; Fax: 91-522-2668017; E-mail: drgyanchandpgi@gmail.com

Received April 06, 2015; Accepted May 07, 2015; Published May 09, 2015

Citation: Kumar A, Ranjan A, Chand G, Kumar D, Singh SK, et al. (2015) The Foot Care Process of Diabetic Patients (With and Without Foot Ulcer) Attending A Tertiary Care Hospital in India. J Stem Cell Res Ther 5: 280. doi:10.4172/2157 7633.1000280

Copyright: (C) 2015 Kumar A, et al. This is an open-access article distributed under the terms of the Creative Commons Attribution License, which permits unrestricted use, distribution, and reproduction in any medium, provided the original author and source are credited. 
(6) To assess the knowledge of diabetic patients about non- weight bearing exercise.

\section{Methods}

\section{Study-sample and setting}

The research approach adopted for the study is comparative survey approach. The research design is qualitative non-experimental research design. The study was conducted in O.P.D. and in ward of endocrine surgery department at SGPGIMS, Lucknow. Diabetic sample size is limited to 400 and categorized into category1 [200 diabetic patient with foot ulcer (DFU+VE)] and category 2 [200 diabetic patient without foot ulcer (DFU-VE)]

\section{Inclusion and exclusion criteria}

The diabetic subjects have either foot ulceration or not. Subjects were excluded if they had severe peripheral vascular disease, dementia, nondiabetic or other conditions that would preclude active participation based on the investigator's judgment.

\section{Outcomes and clinical assessment}

The primary outcome was the knowledge about foot care to the diabetic patients, coming in the OPD of Endocrine Surgery at SGPGIMS. This study will help in educate the diabetic patients about how to care the foot, how to administer the insulin and regulate the diet and also making the diet chart according to blood sugar level as well as manage and regulate the blood sugar by doing exercise. It also educate the patients about how to wear the diabetic shoes, educate about not wearing the toes ring and motivate the patients for regular cheek up and fallow the advice by medical officer.

\section{Methodology}

This is a comparative study carried out from July 2013 to June 2014. The brief questionnaires were administered by medical officers who also examined for predisposing factors to foot ulcer in the patients. The questionnaire consisted of questions on knowledge of foot care and current self-care practice (27 questions), hypoglycaemia and diet (9 questions), insulin administration and importance of exercise (17 questions); and each correct question was assigned one mark. Our questionnaire aids some additional information in some previous studies questionnaire $[11,12]$. The outcome variables of the study were knowledge and practice regarding foot care in diabetic patients.

\section{Statistical analysis}

Data obtained were analysed using SPSS statistical software version 16. Frequency and descriptive statistics were used to examine the general characteristics of the patients. The response to questions on knowledge, practice and barriers to foot care were analysed. Student $t$ test was used to compare the means of the scores and the clinical parameter between DFU+VE and DFU-VE patients; and Chi square test was used to assess the significance of the responses and a $P$ value of $<0.05$ was considered statistically significant.

\section{Results}

We enrolled a total of 400 diabetic patients, 200 were DFU+VE and 200 were DFU -VE. In case of DFU+VE, $140(70 \%)$ and $60(30 \%)$ were males and females respectively while $116(58 \%)$ were males and $84(42 \%)$ females in DFU-VE patients (Table S1). According to the results of the interviews, patients face with different factors during

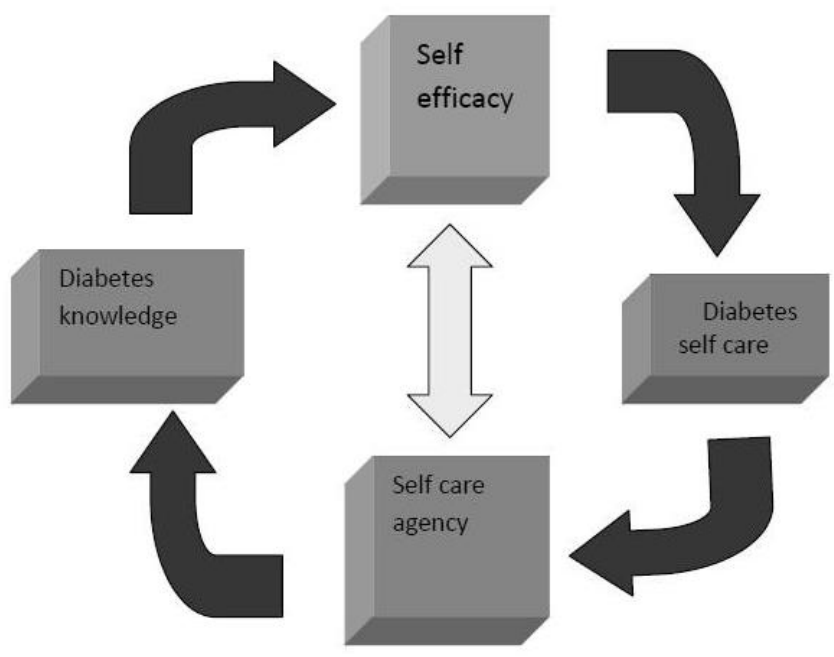

Figure 1: Management and knowledge of diabetes. A conceptual network operates in the management of foot ulcer in diabetic patient. Any irregular flow of network involve in the induction and progression of foot ulcer in diabetic patients.

their experience and thus do a series of actions which could worsen or improve their disease management which is itself related to continuation of care. The findings indicated that the weak management of the disease leads to other diseases and vital complications like foot ulcer. They also showed that the strategies that patients adopt in regard to their foot ulcer are affected by their experiences, awareness and attitudes (Figure 1). The analysis of findings also showed that the experience of the disease and its management are undeniably related to the continuity of care and that disease management, disease experience and continuity of care are effective on the recuperation process of the wound.

\section{Knowledge and practice of foot care}

In DFU+VE patients, $47.7 \%$ had good knowledge of foot care versus $52.3 \%$ had poor knowledge about foot care while in DFU-VE patients, $52 \%$ had good knowledge versus $48 \%$ had poor knowledge about foot care. The distributions, of the response to questions related to the knowledge of foot care were shown in Table 1.

\section{Hypoglycaemia and diet status}

In $\mathrm{DFU}+\mathrm{VE}$ cases, $66.5 \%$ had good knowledge to treat hypoglycaemia at home versus $33.5 \%$ had poor knowledge to treat hypoglycaemia at home; the $74 \%$ had good knowledge of diabetic diet versus $26 \%$ had poor knowledge of diabetic diet. On the other hand, in DFU-VE, $64.5 \%$ had good knowledge to treat hypoglycaemia at home versus $35.5 \%$ had poor knowledge to treat hypoglycaemia at home; the $74 \%$ had good knowledge of diabetic diet versus $26 \%$ had poor knowledge of diabetic diet. The responses related to hypoglycaemia and diet among the diabetic patients, (DFU+VE) and (DFU-VE), were represented in Table 2.

\section{Knowledge of insulin administration and exercise}

The $48.53 \%$ DFU+VE patients had good knowledge of insulin administration versus $51.47 \%$ had poor knowledge of insulin administration; $63.7 \%$ had good knowledge of exercise. The $36.93 \%$ DFU-VE patients had good knowledge of insulin administration versus 


\begin{tabular}{|c|c|c|c|c|}
\hline \multirow{2}{*}{ Questions related to knowledge and practice of foot care } & \multicolumn{2}{|c|}{ DFU+VE } & \multicolumn{2}{|c|}{ DFU-VE } \\
\hline & Correct $(\%)$ & Wrong (\%) & Correct (\%) & Wrong (\%) \\
\hline Are you diabetic patient? & 100 & 0 & 92 & 8 \\
\hline Do you know about diabetes? & 68 & 32 & 88 & 12 \\
\hline How long you have diabetes (Below 25 years)? & 100 & 0 & 94 & 6 \\
\hline Do you know about symptoms of diabetes? & 72 & 28 & 82 & 18 \\
\hline Do you know the complications of diabetes? & 56 & 44 & 66 & 34 \\
\hline Do you know about foot complication in diabetes? & 60 & 40 & 62 & 38 \\
\hline Do you ever have ulcer in your foot? & 24 & 76 & 46 & 54 \\
\hline Do you take advice from qualified doctor? & 26 & 74 & 46 & 54 \\
\hline Does he/she an advice for foot care? & 56 & 44 & 58 & 42 \\
\hline Do you inspect feet regularly? & 54 & 46 & 64 & 36 \\
\hline Do you wash feet every evening regularly? & 54 & 46 & 56 & 44 \\
\hline Do you wash feet with soap and luck warm water? & 38 & 62 & 36 & 64 \\
\hline Do you properly dry in between your toes? & 52 & 48 & 56 & 44 \\
\hline Do you keep feet clean and moist? & 42 & 58 & 36 & 64 \\
\hline Do you use the moisturizing cream over feet? & 40 & 60 & 34 & 66 \\
\hline Do you cut nails with sharp instrument? & 36 & 64 & 20 & 80 \\
\hline Do you use the nail cutter? & 64 & 36 & 74 & 26 \\
\hline Do you trim toes nails straight across? & 44 & 56 & 62 & 38 \\
\hline Do you use the emir board to shape toe nails? & 38 & 62 & 60 & 40 \\
\hline Do you measure your feet size when last you bought footwear? & 86 & 14 & 60 & 40 \\
\hline Do you receive advice when last you bought footwear? & 74 & 26 & 2 & 98 \\
\hline Did you ever inspect inside of footwear? & 74 & 26 & 68 & 32 \\
\hline Do you regularly walk bare footwear? & 50 & 50 & 58 & 42 \\
\hline Are you going to worship place bearing shocks? & 18 & 82 & 24 & 76 \\
\hline Do you change your shocks daily? & 46 & 54 & 70 & 30 \\
\hline Do you wear elasticized hosiery? & 4 & 96 & 18 & 82 \\
\hline Do you wear toe rings? & 58 & 42 & 30 & 70 \\
\hline
\end{tabular}

Table 1: Distribution of the responses to questions related to the knowledge and practice of foot care among the diabetic patients [with foot ulcer (DFU+VE) and without foot ulcers (DFU-VE)].

\begin{tabular}{|c|c|c|c|c|}
\hline \multirow{2}{*}{ Questions related to hypoglycaemia and diet } & \multicolumn{2}{|c|}{ DFU+VE } & \multicolumn{2}{|c|}{ DFU-VE } \\
\hline & Correct $(\%)$ & Wrong (\%) & Correct $(\%)$ & Wrong (\%) \\
\hline Do you know about hypoglycemia? & 68 & 32 & 74 & 26 \\
\hline How to identify the symptoms of hypoglycemia? & 66 & 34 & 68 & 32 \\
\hline Do you know how to treat hypoglycemia? & 66 & 34 & 58 & 42 \\
\hline Do you know how to manage the hypoglycemia at home? & 66 & 34 & 58 & 42 \\
\hline Do you plan your normal routine daily diet, according to modify insulin unit? & 72 & 28 & 88 & 12 \\
\hline Do you manage the time interval between meal and insulin? & 68 & 32 & 90 & 10 \\
\hline Are you able to identify food sources of carbohydrates? & 64 & 36 & 76 & 24 \\
\hline Can you name the common food that should be avoided? & 98 & 2 & 78 & 22 \\
\hline Did you know to substitute food from exchange list? & 60 & 40 & 68 & 32 \\
\hline
\end{tabular}

Table 2: Distribution of the responses to questions related to the hypoglycaemia and diet among the diabetic patients (DFU+VE) and (DFU-VE).

$63.07 \%$ had poor knowledge of insulin administration; $59.6 \%$ had good knowledge of exercise. The queries and their responses were mentioned in Table 3.

\section{Association of demographic factors with the knowledge and practice of foot care, hypoglycaemia and diet, and insulin administration and exercise}

Seventy two (36\%) DFU+VE and eighty-eight (44\%) DFU-VE were below the age of 50 years. The mean age for DFU+VE and DFU-VE and DFU-VE were $55.74 \pm 8.34$ and $51.62 \pm 13.85$ respectively. Of 200 DFU+VE patients, $115(57.4 \%)$ had no formal or primary education and $85(42.6 \%)$ had a secondary or tertiary education; 61 (30.5\%) had upper/middle socioeconomic status. However in case of DFU-VE, $106(52.8 \%)$ had no formal or primary education and $94(47.2 \%)$ had a secondary or tertiary education; $82(41 \%)$ had good socioeconomic status (Table S1).

In order to determine the impact of demographic factors on knowledge and practice of foot care, hypoglycaemia and diet, and insulin administration and exercise in DFU+VE patients, the categorical variables were dichotomized and the student $t$ test was used to compare the mean of the scores. Poor education attainment and low socioeconomic status were significantly associated with lower the knowledge and practice score, hypoglycaemia and diet, and insulin administration and exercise in this study (Table 4).

Statistical relationship of different clinical parameters in diabetic patients (DFU+VE and DFU-VE)

The diabetic patients were significantly related to table 5 parameters 
Citation: Kumar A, Ranjan A, Chand G, Kumar D, Singh SK, et al. (2015) The Foot Care Process of Diabetic Patients (With and Without Foot Ulcer) Attending A Tertiary Care Hospital in India. J Stem Cell Res Ther 5: 280. doi:10.4172/2157-7633.1000280

Page 4 of 6

\begin{tabular}{|c|c|c|c|c|}
\hline \multirow{2}{*}{ Questions related to insulin administration and exercise } & \multicolumn{2}{|c|}{ DFU+VE } & \multicolumn{2}{|c|}{ DFU-VE } \\
\hline & Correct (\%) & Wrong (\%) & Correct (\%) & Wrong (\%) \\
\hline Do you use insulin (Below 10 year)? & 56 & 44 & 56 & 44 \\
\hline How long you are using insulin? & 56 & - & 42 & - \\
\hline Do you know that how many type of insulin are there? & 56 & 44 & 56 & 44 \\
\hline Do you know how to store the insulin? & 64 & 36 & 62 & 38 \\
\hline Do you know to use the insulin? & 52 & 48 & 50 & 50 \\
\hline Do you know about insulin syringe? & 62 & 38 & 54 & 46 \\
\hline Do you know that how many unit of insulin to takes? & 54 & 46 & 68 & 32 \\
\hline Do you know about safe site of insulin injection? & 62 & 38 & 54 & 46 \\
\hline Do you know the right technique of insulin administration? & 56 & 44 & 40 & 60 \\
\hline Do you able to administer insulin yourself? & 52 & 48 & 60 & 40 \\
\hline Do you clean the site of insulin administration with spirit swab? & 82 & 18 & 66 & 34 \\
\hline Do you know to alternately change the site? & 72 & 28 & 60 & 40 \\
\hline Do you know after the insulin administration site should not be rubbed? & 34 & 66 & 54 & 46 \\
\hline Do you walk regularly? & 62 & 38 & 72 & 28 \\
\hline What duration you walk in a day (\% of below $4 \mathrm{~km})$ ? & 58 & 42 & 70 & 30 \\
\hline Do you doing any type of exercise? & 42 & 58 & 54 & 46 \\
\hline Duration of that exercise ( $\%$ of below 3 hours)? & 42 & 58 & 54 & 46 \\
\hline
\end{tabular}

Table 3: Distribution of the responses to questions related to the insulin administration and exercise among the diabetic patients (DFU+VE and DFU-VE).

\begin{tabular}{|c|c|c|c|c|c|c|}
\hline Demographic factors & Knowledge and practice score & $p$ value & Hypoglycaemia and diet score & $p$ value & Insulin administration and exercise score & $p$ value \\
\hline $\begin{array}{l}\text { Age } \\
<50 \\
\geq 50\end{array}$ & $\begin{array}{l}14.84 \\
14.39\end{array}$ & 0.58 & $\begin{array}{l}4.56 \\
4.27\end{array}$ & 0.39 & $\begin{array}{l}9.48 \\
9.37\end{array}$ & 0.74 \\
\hline $\begin{array}{l}\text { Sex } \\
\text { Male } \\
\text { Female }\end{array}$ & $\begin{array}{l}15.57 \\
15.28\end{array}$ & 0.37 & $\begin{array}{l}4.83 \\
4.53\end{array}$ & 0.42 & $\begin{array}{l}10.79 \\
10.65\end{array}$ & 0.40 \\
\hline $\begin{array}{l}\text { Education } \\
\text { None/Primary } \\
\text { Secondary/Tertiary }\end{array}$ & $\begin{array}{l}15.48 \\
17.53\end{array}$ & 0.005 & $\begin{array}{l}5.81 \\
4.56\end{array}$ & 0.043 & $\begin{array}{c}9.87 \\
11.16\end{array}$ & 0.003 \\
\hline $\begin{array}{l}\text { Socioeconomic status } \\
\text { Upper/Middle } \\
\text { Lower }\end{array}$ & $\begin{array}{l}17.91 \\
14.62\end{array}$ & 0.042 & $\begin{array}{l}5.94 \\
3.87\end{array}$ & 0.011 & $\begin{array}{l}11.36 \\
9.18\end{array}$ & 0.035 \\
\hline
\end{tabular}

Table 4: Impact of demographic factors on knowledge and practice of foot care in DFU+VE cases.

\begin{tabular}{|c|c|c|c|}
\hline Clinical Parameters & $\begin{array}{c}\mathrm{DFU}+\mathrm{VE} \\
(\text { mean } \pm \mathrm{SD})\end{array}$ & $\begin{array}{c}\text { DFU-VE } \\
(\text { mean } \pm \text { SD) }\end{array}$ & $P$ value \\
\hline Are you diabetic patient? (Q1) & $1 \pm 0.01$ & $0.92 \pm 0.27$ & 0.042 \\
\hline Do you know about diabetes? (Q2) & $0.68 \pm 0.47$ & $0.88 \pm 0.33$ & 0.016 \\
\hline How long you have diabetes? (Q3) & $14.80 \pm 2.94$ & $9.54 \pm 7.44$ & $<0.001$ \\
\hline Do you ever have ulcer in your foot? (Q4) & $0.24 \pm 0.43$ & $0.46 \pm 0.50$ & 0.021 \\
\hline Do you take advice from qualified doctor? (Q5) & $0.26 \pm 0.44$ & $0.46 \pm 0.50$ & 0.038 \\
\hline Do you measure your feet size when last you bought footwear? (Q6) & $0.38 \pm 0.49$ & $0.60 \pm 0.49$ & 0.028 \\
\hline Do you receive advice when last you bought footwear? (Q7) & $0.86 \pm 0.35$ & $0.60 \pm 0.49$ & 0.003 \\
\hline Do you wear elasticized hosiery? (Q8) & $0.48 \pm 0.54$ & $0.70 \pm 0.46$ & 0.032 \\
\hline Do you plan your normal routine daily diet, according to modify insulin unit? (Q9) & $1.34 \pm 0.63$ & $1.90 \pm 0.42$ & $<0.001$ \\
\hline Do you manage the time interval between meal and insulin? (Q10) & $1.36 \pm 0.60$ & $1.90 \pm 0.42$ & $<0.001$ \\
\hline Can you name the common food that should be avoided? (Q11) & $0.98 \pm 0.141$ & $0.78 \pm 0.42$ & 0.002 \\
\hline Do you know the right technique of insulin administration? (Q12) & $0.46 \pm 0.50$ & $0.24 \pm 0.43$ & 0.021 \\
\hline How long you walk? (Q13) & $1.62 \pm 0.75$ & $1.26 \pm 0.88$ & 0.030 \\
\hline What duration you walk in a day? (Q14) & $0.28 \pm 0.54$ & $0.70 \pm 0.84$ & 0.004 \\
\hline
\end{tabular}

Table 5: The relationship of different clinical parameters in Diabetic patients (DFU+VE) and (DFU-VE).

like Q1 $(p=0.042)$, Q2 ( $p=0.016), \mathrm{Q} 3(p=<0.001)$, Q4 $((p=0.021)$, $\mathrm{Q} 5(p=0.038), \mathrm{Q} 6((p=0.028), \mathrm{Q} 7(p=0.003), \mathrm{Q} 8(p=0.032), \mathrm{Q} 9(p=$ $<0.001), \mathrm{Q} 10((p=<0.001), \mathrm{Q} 11((p=0.002), \mathrm{Q} 12((p=0.021), \mathrm{Q} 13(p=$ $0.030)$ and Q14 $(p=0.004)$. The other studied parameter showed no significant result (Table 5).

\section{Discussion}

The result of this study showed that a greater proportion of diabetic patients had a poor knowledge of diabetic foot care. The lack of knowledge foot care in our study is consistent with findings by other investigators worldwide [12-16].

We also found that the DFU-VE patients (52\%) had good knowledge of foot care in comparison to DFU+VE patients (47.7\%). The status of diet and how to treat hypoglycaemia were approximately similar in both groups. However, DFU+VE patients had good knowledge of insulin administration in comparison of DFU-VE patients. A network of different pathway and various environmental factors are responsible 
for the progression of the benign to lethal stages of diabetes. Therefore, the lack of knowledge of foot care, by several means, responsible for formation of ulcer in different diabetic patients.

In the present study, the patients having poor education and in low status significantly had lower knowledge of foot care while gender and age differences were not significantly associated with the knowledge of foot care. Our study had same concordance with previous studies in India, Iran and Pakistan [13-15]. The knowledge of appropriate foot care has been suggested to be positively influenced by patient education which in turn reduces the risk of foot ulceration and amputation in high-risk diabetics [17]. The association between education and knowledge may be due to the fact that, educated patient were able to read and understand some of educational supportive materials and also use information technology to obtain more information about the disease.

In the present non-experimental survey based study, although, patients recruited on the basis of presence of diabetes yet patients either had foot ulcer or they don't have ulcer. This is the difference of this study that that of other previous studies [12-16]. Patient's unawareness about the presence of diabetic disease, disease process, the normal level of blood sugar, the effect of medicinal diet, type of nutritional diet, care process for the foot and preventing the ulcer $[13,18]$. The likelihood for the occurrence of ulcer following the diabetic disease, presence of the diabetic association, and access to training classes results in the weak management of the disease and accordingly in the deterioration of the foot ulcer. The rate of amputation among the patients who suffer from the diabetic foot ulcer syndrome and have a weak control over their blood sugar is much higher [19]. Women and those above the age of 50 were less knowledgeable about foot care, although these associations were not statistically significant. Some factor also influence the poor knowledge of foot care is that in some third world countries due to socio-cultural beliefs women are not allowed to attain higher educational status compared with their male counterpart in the family, eventually resulting in women having less knowledge of DM foot care.

Some of the inadequacies of foot care practice in our subjects include non-inspection of ulcer inside foot (76\% DFU+VE versus 54\% DFU-VE patients), non-inspection of their feet (46\% DFU+VE versus $36 \%$ DFU-VE), improper washing of feet with soap and warm water (62\% DFU+VE versus 64\% DFU-VE), and no advice from doctor $(74 \%$ $\mathrm{DFU}+\mathrm{VE}$ versus 54\% DFU-VE). The poor practice of foot care in this study may be attributed to the lack of knowledge among the respondent as $52.3 \% \mathrm{DFU}+\mathrm{VE}$ versus $48 \% \mathrm{DFU}-\mathrm{VE}$ patients had poor knowledge of foot care.

The deficiency in the knowledge may be due to poor communication between the doctors and the patients and also lack of counselling by the doctors and nurses as result of busy clinic schedule. Thus, patient education on the prevention of foot ulceration is imperative and should be incorporated into the routine care of patients with diabetes both in the hospital and in the community. Time must be allotted to communication, information and education during clinic sessions [20]. Furthermore, the education of physician is highly imperative to complement and reinforce the behaviours of patient with regards to foot care; they need to learn and imbibe the skills of counselling and risk assessment. Our study has been able to determine the knowledge and practice of foot care among diabetic patients, with and without foot ulcer, in Indian.

\section{Strengths and Limitations of the Study}

The results of this study are a wakeup call on the clinicians, nurses and researchers etc. (a diabetic team) to establish a patients and diabetic team friendly educational programmes that will enhance and sustain the good knowledge and practice of foot care. The study has unique strengths in which different clinical parameters were questioned in diabetic patients (with and without foot ulcer). The limitation of this study was that it is centred to a specific tertiary care hospital (SGPGIMS, Lucknow) in India, and only in limited number of samples.

\section{Conclusions}

In conclusion, the knowledge and practice of foot care among diabetic patients (with and without foot ulcer) in study were poor. The various pathways and factors contribute to recuperation of the diabetic foot ulcer. The most important ones are the disease experiences and disease management and also the continuity of caring. Attending to the latter point and having team therapy with a systematic program and continuous training for the patients alongside establishing specialist care centres for diabetic patients and employing trained nurses with specialty in foot diseases lead to the proper management of the disease and further participation from patients which consequently play a significant role in the recuperation of the foot ulcer syndrome.

\section{Acknowledgements}

The authors are thankful to Sanjay Gandhi Post Graduate institute of Medical Sciences, Lucknow (India) for providing infrastructure facility. No sponsors were involved in this retrospective study and all the authors declare contributed equally and they had no conflict of interest.

\section{References}

1. Eastman RC, Javitt JC, Herman WH, Dasbach EJ, Zbrozek AS, et al. (1997) Model of complications of NIDDM. II. Analysis of the health benefits and costeffectiveness of treating NIDDM with the goal of normoglycemia. Diabetes Care 20: 735-744. [PubMed]

2. Wild S, Roglic G, Green A, Sicree R, King H (2004) Global prevalence of diabetes: estimates for the year 2000 and projections for 2030. Diabetes Care 27: 1047-1053. [PubMed]

3. Vijan S, Stevens DL, Herman WH, Funnell MN, Staniford CJ (1997) Screening prevention, counseling, and treatment for the complications of type II diabetes mellitus. Putting evidence into practice. J Gen Intern Med 12: 567-580. [PubMed]

4. Bartus $\mathrm{Cl}$, Margolis DI (2004) Reducing the incidence of foot ulceration and amputation in diabetes. Curr Diab Rep 4: 413-418. [PubMed]

5. International Diabetes Federation Time to Act: diabetes and foot care (2005) Brussels: International Diabetes Federation.

6. Nyamu PN, Otieno CF, Amayo EO, McLigeyo SO (2003) Risk factors and prevalence of diabetic foot ulcers at Kenyatta National Hospital, Nairobi. East Afr Med J 80: 36-43. [PubMed]

7. Bouter KP, Storm AJ, de Grost RR, Uitslager R, Erkelena DW, et al. (1993) The diabetic foot in Dutch hospitals: epidemiological features and clinical outcome. Eur J Med 2: 215-218. [PubMed]

8. Ogbera AO, Fasanmade O, Ohwovoriole AE, Adediran $\mathrm{O}$ (2006) An assessmen of the disease burden of foot ulcers in patients with diabetes mellitus attending a teaching hospital in Lagos, Nigeria. Int J Low Extrem Wounds 5: 244-249. [PubMed]

9. Sicree R, Shaw J, Zimmet P (2006) Diabetes and impaired glucose tolerance. (3rdedn), International Diabetes Federation, Belgium.

10. Abbas ZG, Archibald LK (2005) Epidemiology of the diabetic foot in Africa. Med Sci Monit 11: RA262-270. [PubMed]

11. American Diabetes Association (1998) Foot care in patients with diabetes mellitus. Diabetes Care 21: S54-55.

12. Pollock RD, Unwin NC, Connolly V (2004) Knowledge and practice of foot care in people with diabetes. Diabetes Res Clin Pract 64: 117-122. [PubMed]

13. Khamseh ME, Vatankhah N, Baradaran HR (2007) Knowledge and practice of foot care in Iranian people with type 2 diabetes. Int Wound J 4: 298-302. [PubMed] 
Citation: Kumar A, Ranjan A, Chand G, Kumar D, Singh SK, et al. (2015) The Foot Care Process of Diabetic Patients (With and Without Foot Ulcer) Attending A Tertiary Care Hospital in India. J Stem Cell Res Ther 5: 280. doi:10.4172/2157-7633.1000280

Page 6 of 6

14. Hasnain S, Sheikh NH (2009) Knowledge and practices regarding foot care in diabetic patients visiting diabetic clinic in Jinnah Hospital, Lahore. J Pak Med Assoc 59: 687-690. [PubMed]

15. Viswanathan V, Shobhana R, Snehalatha C, Seena R, Ramachandran A (1999) Need for education on foot care in diabetic patients in India. J Assoc Physicians India 47: 1083-1085. [PubMed]

16. Aliasgharpour M, Nayeri ND (2012) The care process of diabetic foot ulcer patients: a qualitative study in Iran. J Diabetes Metab Disord 11: 27. [PubMed]
17. Singh N, Armstrong DG, Lipsky BA (2005) Preventing foot ulcers in patients with diabetes. JAMA 293: 217- 228. [PubMed]

18. Vatankhah N, Khamseh ME, Noudeh YJ, Aghili R, Baradaran HR, et al. (2009) The effectiveness of foot care education on people with type 2 diabetes in Tehran, Iran. Prim Care Diabetes 3: 73-77. [PubMed]

19. Jaffiol C (2009) Current management of type 2 diabetes in France. Bull Acad Natl Med 193: 1645-1661. [PubMed]

20. Fletcher $J(2006)$ Full nursing assessment of patients at risk of diabetic foot ulcer. Br J Nurs 15: S18-S21. [PubMed] 